\title{
DESENVOLVIMENTO DE UM SISTEMA DE PCR MULTIPLEX PARA A CARACTERIZAÇÃO MOLECULAR DE CEPAS DO TRYPANOSOMA CRUZI EM SUAS PRINCIPAIS LINHAGENS FILOGENÉTICAS
}

\author{
Thalissa P. de Souza1, ${ }^{1,}$, Cláudia de Souza², Débora de O. Lopes² \\ Luciana L. Santos ${ }^{2}$, Nayara D. A. Bortoleto ${ }^{1}$, Andréa M. Macedo ${ }^{3}$, Helder \\ M.S.Valadares ${ }^{1}$ \\ 1Laboratório de Genética Molecular, Universidade Federal de São João Del-Rei, \\ Divinópolis/MG \\ 2Laboratório de Biologia Molecular, Universidade Federal de São João Del-Rei, \\ Divinópolis/MG \\ 3Laboratório de Genética Bioquímica, Universidade Federal de Minas Gerais, Belo Horizonte/MG \\ *e-mail: thalissa.prado@hotmail.com
}

\section{Resumo}

O Trypanosoma cruzi, agente etiológico da doença de Chagas, apresenta uma grande heterogeneidade genética atribuída ao seu modo de reprodução predominantemente clonal. Após décadas de pesquisa, vários marcadores moleculares foram descritos para o $T$. cruzi e com base em seus perfis eletroforéticos, um grupo de pesquisadores estabeleceu um consenso para a nomenclatura do $T$. cruzi: as cepas do $T$. cruzi são referidas como Discretas Unidades Taxonômicas (DTUs) chamadas de T. cruzi I a T. cruzi VI. Entretanto, ainda não existe um consenso sobre quantos e quais marcadores devem ser utilizados para uma classificação adequada das cepas do T. cruzi. Então, visando aperfeiçoar o procedimento de caracterização molecular do $T$. cruzi em suas principais linhagens filogenéticas, este trabalho tem como objetivo padronizar um sistema de PCR multiplex contendo três marcadores polimórficos: os genes Citocromo Oxidase II, Mini-éxon e rDNA 24S $\alpha$. Uma vez que estes marcadores apresentavam diferentes sistemas de amplificação por PCR, foi necessário estabelecer novas condições que permitissem a amplificação simultânea dos três marcadores e testar a especificidade do sistema de PCR multiplex empregando DNA de várias cepas do T. cruzi. Os resultados revelaram que todos os pares de iniciadores foram eficientemente amplificados e exibiram os padrões de 
amplificação esperados (exceto para o gene COII). Ao avaliar a sensibilidade do sistema multiplex, foram observadas amplificações positivas somente até o nível de 10pg de DNA sugerindo que novos ensaios devem ser realizados para conseguir uma amplificação positiva até o nível 100 fentogramas. Com a padronização deste sistema de PCR multiplex novas possibilidades nos processos de caracterização molecular do $T$. cruzi serão alcançadas permitindo determinar com segurança a DTU para as cepas do T. cruzi empregando uma única amostra de DNA.

Palavras-chave: Trypanosoma cruzi, PCR multiplex, marcadores moleculares. 